\title{
Heterogeneity of Nicotinic Receptor Class and Subunit mRNA Expression among Individual Parasympathetic Neurons from Rat Intracardiac Ganglia
}

\author{
Kevin Poth, Thomas J. Nutter, Javier Cuevas, Michael J. Parker, David J. Adams, and Charles W. Luetje \\ Department of Molecular and Cellular Pharmacology, University of Miami School of Medicine, Miami, Florida 33101
}

Neurons have the potential to form thousands of distinct neuronal nicotinic receptors from the eight $\alpha$ and three $\beta$ subunits that currently are known. In an effort to determine how much of this potential complexity is realized among individual neurons, we examined the nicotinic pharmacological and biophysical properties and receptor subunit mRNA expression patterns in individual neurons cultured from rat epicardial ganglia. Analysis of the whole-cell pharmacology of these neurons showed a diversity of responses to the agonists acetylcholine, nicotine, cytisine, and 1,1-dimethyl-4-phenylpiperazinium, suggesting that a heterogeneous population of nicotinic receptor classes, or subtypes, is expressed by individual neurons. Singlechannel analysis demonstrated three distinct conductances $(18,24$, and $31 \mathrm{pS})$, with patches from different neurons containing different combinations of these channel classes. We used single-cell RT-PCR to examine nicotinic acetylcholine receptor ( $\mathrm{AAChR}$ ) subunit mRNA expression by individual neurons. Although mRNAs encoding all eight neuronal nAChR subunits for which we probed $(\alpha 2-\alpha 5, \alpha 7, \beta 2-\beta 4)$ were present in multicellular cultures, we found that individual epicardial neurons express distinct subsets of these nAChR subunit mRNAs. These results suggest that individual epicardial neurons express distinct arrays of $\mathrm{nAChR}$ subunits and that these subunits may assemble into functional receptors with distinct and variable subunit composition. This variable receptor subunit expression provides an explanation for the diversity of pharmacological and single-channel responses we have observed in individual neurons.

Key words: neuronal nicotinic receptors; nicotinic acetylcholine receptors; cardiac ganglia; parasympathetic ganglia; singlecell RT-PCR; nicotinic pharmacology
The neuronal nicotinic acetylcholine receptor (nAChR) subunit gene family currently consists of eleven members: $\alpha 2-\alpha 9$ and $\beta 2-\beta 4$ (Sargent, 1993; Elgoyhen et al., 1994). Neuronal nAChRs are thought to have an architecture similar to that of muscle nAChRs: a pentameric assembly of subunits surrounding an ion pore. The existence of eleven subunits suggests that a neuron could express nAChRs with a variety of subunits and could express multiple distinct nAChR classes that differ in subunit composition. Insight into receptor composition can be attained by examining those subunit combinations that form functional receptors in exogenous expression systems and by identifying which combinations actually are expressed by neurons.

Expression studies using Xenopus oocytes suggest that functional neuronal nAChRs can be formed by pairwise combinations of one kind of $\alpha$ and one kind of $\beta$ subunit (Boulter et al., 1987; Wada et al., 1988; Duvoisin et al., 1989) in a stoichiometry of two $\alpha$ and three $\beta$ (Anand et al., 1991; Cooper et al., 1991) or, in some

Received June 21, 1996; revised Oct. 22, 1996; accepted Oct. 24, 1996.

This work was supported by grants to C.W.L. from the American Heart Association Florida affiliate, the Pharmaceutical Research and Manufacturers of America Foundation, and the National Institute on Drug Abuse (DA08102), and to D.J.A. from the National Heart, Lung, and Blood Institute (HL35422). C.W.L. was an Initial Investigator of the American Heart Association Florida affiliate. We thank Drs. Richard Bookman, Richard Kramer, and Jim Patrick for critical reading of this manuscript.

Correspondence should be addressed to Dr. Charles W. Luetje, Department of Molecular and Cellular Pharmacology (R-189), University of Miami School of Medicine, P.O. Box 016189, Miami, FL 33101.

Dr. Cuevas's present address: Department of Biology, University of California, San Diego, CA 92093.

Dr. Adams's present address: Department of Physiology and Pharmacology, University of Queensland, Brisbane QLD 4072, Australia.

Copyright (C) 1997 Society for Neuroscience 0270-6474/97/170586-11\$05.00/0 cases, as homomeric assemblies (Schoepfer et al., 1990; Séguéla et al., 1993; Elgoyhen et al., 1994). Complex subunit combinations are also possible, because receptors containing more than one distinct $\alpha$ or $\beta$ subunit have been shown to form in oocytes (Colquhoun et al., 1993; Ramirez-Latorre et al., 1996). Both $\alpha$ and $\beta$ subunits make contributions to the pharmacological and biophysical properties of these receptors, giving each distinct subunit combination unique characteristics (Wada et al., 1988; Duvoisin et al., 1989; Papke et al., 1989; Luetje et al., 1990; Luetje and Patrick, 1991; Papke and Heinemann, 1991).

Immunoprecipitation experiments have identified a nAChR in rat brain composed of $\alpha 4$ and $\beta 2$ subunits, as well as a nAChR in chick ciliary ganglion containing the $\alpha 3, \alpha 5$, and $\beta 4$ subunits (Flores et al., 1991; Vernallis et al., 1993). Pharmacological analysis suggests that the $\beta 2$ and $\beta 4$ subunits may coassemble into the same receptor in rat sympathetic neurons (Mandelzys et al., 1995), and a preliminary report suggests formation of neuronal nAChRs of even more complex composition (Forsayeth et al., 1995). Electrophysiological studies have shown that individual neurons can express several distinct nAChR conductance classes (Mathie et al., 1991; Adams and Nutter, 1992; Moss and Role, 1993). This expression of multiple nAChR classes by individual neurons is a complicating factor in attempts to use oocyte expression data to identify $\mathrm{nAChR}$ subunit composition in neurons (Covernton et al., 1994).

We now show that the whole-cell nicotinic agonist pharmacology of intracardiac parasympathetic neurons varies dramatically among individual neurons, and we provide evidence of singlechannel behavior suggesting a heterogeneous population of nAChRs on these neurons. Then, using RT-PCR analysis, we 


\begin{tabular}{|c|c|c|c|c|c|c|c|}
\hline \multirow{2}{*}{$\frac{\text { Subunit }}{\alpha 2}$} & \multirow{2}{*}{$\begin{array}{l}\text { Range } \\
665-1215\end{array}$} & \multicolumn{2}{|c|}{ Primer sequence } & \multirow{2}{*}{$\begin{array}{l}\text { Enzyme } \\
\text { BspD1 }\end{array}$} & \multicolumn{3}{|c|}{ Fragments } \\
\hline & & FWD & GACATCGTCCTCTACAACAAYGCDGAT & & $\underline{348}$ & 125 & 78 \\
\hline & & REV & AGCGGGATGACCAGCGAGGTGGAMGG & & & & \\
\hline$\alpha 3$ & $490-1040$ & & & Ava 1 & $\underline{279}$ & $\underline{272}$ & \\
\hline$\alpha 4$ & 379-929 & & & Aat 2 & $\underline{420}$ & 131 & \\
\hline \multirow[t]{2}{*}{$\beta 2$} & $534-1075$ & FWD & GACGTCGTGCTATACAACAATGCYGAYGG & Nhe1 & $\underline{474}$ & 49 & \\
\hline & & REV & AGCGGTACGTCGAGGGAGGTGGGAGG & & & & \\
\hline$\beta 4$ & $402-943$ & & & Afl 2 & $\underline{327}$ & $\underline{214}$ & \\
\hline \multirow[t]{2}{*}{$\alpha 5$} & $336-1058$ & FWD & ACGACGAATGTCTGGYTGAAGCAGG & Sal1 & $\underline{383}$ & $\underline{340}$ & \\
\hline & & REV & GGCAAAGACAGTCACCATAATGGATAGGG & & & & \\
\hline \multirow[t]{2}{*}{$\beta 3$} & $280-810$ & FWD & ACGACGAATGTCTGGYTGAAGCAGG & Nco 1 & $\underline{236}$ & $\underline{219}$ & 75 \\
\hline & & REV & GACCGTGAGAAAAGACAACCCCAGG & & & & \\
\hline \multirow[t]{2}{*}{$\alpha 7$} & $338-813$ & FWD & GGAGTGAAGAATGTTCGTTTTCCAGATGG & $\mathrm{Hae} 2$ & $\underline{398}$ & 78 & \\
\hline & & REV & AGCAAGAATACCAGCAGAGCCAGGG & & & & \\
\hline
\end{tabular}

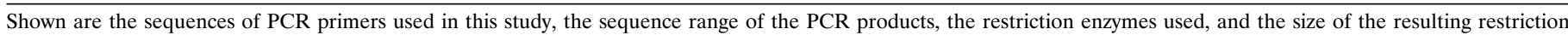

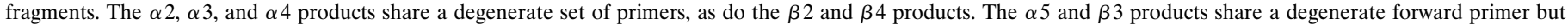
have specific reverse primers. Digestion fragments used to identify particular products are underlined.

demonstrate that, although cultures of these neurons express a wide array of neuronal nAChR subunit mRNAs, individual neurons express distinct subsets of these mRNAs. Taken together, these results suggest that individual intracardiac neurons express distinct combinations of several different nAChR subtypes.

\section{MATERIALS AND METHODS}

Materials. Collagenase was purchased from Worthington Biomedical (Freehold, NJ). DMEM (containing $10 \mathrm{~mm}$ glucose) was obtained from Life Technologies (Grand Island, NY). Fetal calf serum, penicillin/streptomycin, laminin, $\mathrm{Na}_{4}$ BAPTA, HEPES-NaOH, acetylcholine (ACh), cytisine, 1,1-dimethyl-4-phenylpiperazinium (DMPP), and nicotine were obtained from Sigma (St. Louis, MO). dNTPs, RNAsin ribonuclease inhibitor, and Maloney murine leukemia virus (MMLV) reverse transcriptase were purchased from Promega (Madison, WI). Random hexamers and S-400 micro spin columns were obtained from Pharmacia Biotech (Piscataway, NJ). All restriction endonucleases were obtained from New England Biolabs (Beverly, MA). PCR primers were synthesized in an on-site facility at the University of Miami.

Cell culture. Neurons from rat atria were isolated and cultured as previously described (Fieber and Adams, 1991). Atria were dissected from neonatal (2-7 d postpartum) rats and incubated in Krebs solution containing $1 \mathrm{mg} / \mathrm{ml}$ collagenase for $1 \mathrm{hr}$ at $37^{\circ} \mathrm{C}$. Intracardiac ganglia were dissected from the atria and transferred to a sterile culture dish containing culture medium [DMEM with $10 \mathrm{mM}$ glucose, $10 \%$ (v/v) fetal calf serum, $100 \mathrm{U} / \mathrm{ml}$ penicillin, and $0.1 \mathrm{mg} / \mathrm{ml}$ streptomycin], triturated with a fire-polished Pasteur pipette, and then plated onto $18 \mathrm{~mm}$ glass coverslips coated with laminin. The dissociated cells were incubated at $37^{\circ} \mathrm{C}$ under a $95 \%$ air $/ 5 \% \mathrm{CO}_{2}$ atmosphere. Experiments were performed on cells maintained in tissue culture for 36-72 hr. At the time of experiments, the glass coverslip was transferred to a low volume $(0.5 \mathrm{ml})$ recording chamber and viewed at $400 \times$ magnification with an inverted, phase-contrast microscope.

Recording conditions. Agonist-induced responses were measured under voltage clamp in isolated neurons with standard patch-clamp techniques (Hamill et al., 1981). Patch pipettes were pulled from borosilicate glass and had tip resistances of 2-5 $\mathrm{M} \Omega$. Membrane currents were recorded with a List EPC-7 patch-clamp amplifier, filtered at $10 \mathrm{kHz}(-3 \mathrm{~dB})$ with a low-pass Bessel filter (4-pole, Ithaco 4302, Ithaca, NY), and stored on videotape using an A/D recorder adapter (PCM-1; Medical Systems, NY). Whole-cell currents were monitored with a chart recorder, and individual current traces were recorded on disk with the Axotape program (Axon Instruments, Foster City, CA) for subsequent analysis. Peak current amplitude elicited by each agonist was measured by cursor with the Axotape program.

The extracellular physiological salt solution (PSS) for voltage-clamp experiments consisted of (in $\mathrm{mM}$ ): $140 \mathrm{NaCl}, 1 \mathrm{CaCl}_{2}, 7.7$ glucose, and 10 histidine, $\mathrm{pH}$ 7.2. The intracellular pipette solution for whole-cell and excised outside-out patch recordings contained (in $\mathrm{mm}$ ): $130 \mathrm{NaCl}, 2$ $\mathrm{Na}_{2} \mathrm{ATP}, 5 \mathrm{Na}_{4} \mathrm{BAPTA}$, and 10 HEPES-NaOH, pH 7.2. Agonistmediated whole-cell responses were evoked by brief (10 msec, $15 \mathrm{psi})$ focal application of ACh, cytisine, DMPP, and nicotine dissolved in PSS at concentrations of $100 \mu \mathrm{M}$ via a pressure ejection device through an extracellular pipette located $50 \mu \mathrm{m}$ from the neuronal soma. Each agonist was applied 2-5 times in random order, and responses to ACh were compared at the start and end of each experiment to ensure the stability of the recording conditions. So that receptor desensitization could be minimized, a delay of $\sim 1$ min separated individual pulses of agonist application, and recordings were made during continuous perfusion of the recording chamber $(\sim 2 \mathrm{ml} / \mathrm{min})$ with PSS.

The outside-out patch configuration was used to record unitary currents to verify the ACh dependence of the single-channel currents. Patch pipettes were pulled from thick-walled borosilicate glass and had tip resistances of 8-15 $\mathrm{M} \Omega$. To decrease noise at high bandwidth, we coated patch electrodes with dental wax. ACh-evoked unitary currents were filtered at $3 \mathrm{kHz}$ (4-pole low-pass Bessel filter) and sampled at $15 \mathrm{kHz}$ (Tecmar Labmaster DMA interface) with a threshold detection device (AI2020A event detector, Axon Instruments) for analysis on a PC 80486 computer using pCLAMP programs (Axon Instruments). The bath contained $1 \mu \mathrm{M} \mathrm{AChCl}$ dissolved in PSS. All numerical data, except where noted, are presented as the mean \pm SEM, with the number of experiments in parentheses.

Cytoplasm harvest of individual neurons. The cellular contents of individual neurons were obtained by applying suction on a patch pipette in the whole-cell recording configuration. The pipettes were filled with sterile intracellular pipette solution. The contents of the pipette $(4-6 \mu \mathrm{l})$ were expelled into a microfuge tube, quickly frozen on dry ice, and stored at $-80^{\circ} \mathrm{C}$ for up to $48 \mathrm{hr}$. Negative controls were obtained by aspirating extracellular solution near the location of the harvested neuron into a separate pipette. This control was carried through all subsequent reactions to exclude the possibility of false positives caused by contamination with cytoplasm from nearby cells or by contamination with nAChR subunit cDNAs used routinely in the laboratory.

Reverse transcription. Total RNA present in the isolated neuronal cytoplasm was reverse-transcribed in a $20 \mu \mathrm{l}$ reaction (1 mM each dNTP, $100 \mathrm{pmol}$ of random hexamers, $20 \mathrm{U}$ of ribonuclease inhibitor, and $40 \mathrm{U}$ of MMLV reverse transcriptase) for $1 \mathrm{hr}$ at $37^{\circ} \mathrm{C}$. Total RNA from rat brain or whole dishes of dissociated cardiac neurons were isolated by using the protocol of Chomczynski and Sacchi (1987). A "template minus" negative control was initiated at the beginning of the RNA isolation.

PCR primers and controls. A set of degenerate primers was designed to amplify each nAChR subunit cDNA (Table 1 ). One primer pair annealed to $\alpha 2, \alpha 3$, and $\alpha 4$; one primer pair annealed to $\beta 2$ and $\beta 4$; one primer pair annealed to $\alpha 5$ and $\beta 3$; the $\alpha 7$ subunit required a specific primer pair. Degenerate primers were used to reduce the number of PCR reactions into which we would divide the reverse-transcribed cytoplasm from a 
single neuron. The use of PCR as an analysis tool, especially with the use of degenerate primers, required us to address several concerns. First, the possibility of contamination by $\mathrm{nAChR}$ subunit cDNAs used routinely in the laboratory was ruled out by inclusion of a template minus negative control in every experiment (as described above). Second, the possibility that we had amplified genomic DNA was obviated by the fact that the primers were designed so that an intron-exon boundary was located either within a primer sequence or between the two primers. Third, the possibility of false positives caused by primers annealing to untargeted cDNA was ruled out by our use of a restriction digestion identification strategy (see below). Fourth, because we were using a degenerate set of primer pairs, the concern of potential "primer bias" had to be addressed and is discussed in Results. Fifth, the potential for variability in our amplification protocol had to be considered. This did not seem to be a problem for identification of $\alpha 3$ mRNA, because every neuron was positive for $\alpha 3$ (Table 2). However, for other subunits, such as $\alpha 7$, only a subset of the neurons presented in Table 2 was found to be positive.

The possibility that this result might be attributable to variability in our amplification protocol is addressed in the following control experiment. Reverse-transcribed neuronal cytoplasms were each divided into five aliquots. One aliquot was amplified with the $\alpha 2 / 3 / 4$ primer set as a positive control to rule out failure caused by RNA degradation. The other four aliquots were each amplified with the $\alpha 7$ primer set. Of the neurons positive for the $\alpha 2 / 3 / 4$ product, two neurons were negative for $\alpha 7$ in all four aliquots, whereas one neuron was positive for $\alpha 7$ in all four aliquots. This control experiment suggests that a negative result in the amplification reaction for some subunit mRNAs in some neurons is not attributable to variability in the amplification protocol but is a reflection of the subunit mRNA expression pattern of that neuron.

Polymerase chain reaction. The RT reaction was divided into aliquots, one for each primer pair, and taken to the first-round PCR by addition of $10 \times$ PCR buffer, $1 \mathrm{mM}$ dNTPs, $2.5 \mathrm{mM} \mathrm{MgCl}_{2}, 10 \mathrm{pmol}$ of each primer, $1.25 \mathrm{U}$ Taq polymerase, and $\mathrm{dH}_{2} \mathrm{O}$ to a final volume of $50 \mu \mathrm{l}$. PCR was performed using a Perkin-Elmer TC-1 (Norwalk, CT). The cycling parameters were five cycles of $94^{\circ}$ for $1 \mathrm{~min}, 55^{\circ}$ for $2 \mathrm{~min}$, ramp to $72^{\circ}$ in $51 \mathrm{sec}$, and $72^{\circ}$ for $1.5 \mathrm{~min}$, followed by 35 cycles of $94^{\circ}$ for $1 \mathrm{~min}, 65^{\circ}$ for $2 \mathrm{~min}$, and $72^{\circ}$ for $1.5 \mathrm{~min}$. Excess primers and primer dimers were removed with $\mathrm{S}-400$ micro spin columns. Then a second round of PCR was performed with the same set of primers and reagents at the same concentrations as in the first round. The cycling parameters for the second round were 35 cycles of $94^{\circ}$ for $1 \mathrm{~min}, 65^{\circ}$ for $2 \mathrm{~min}$, and $72^{\circ}$ for $1.5 \mathrm{~min}$. These second-round products were gel-purified. In some experiments, the $\alpha 5$ and $\beta 3$ products were amplified separately.

Restriction digestion. To identify which subunit sequences are present in the second-round PCR products, we developed a restriction digestion strategy such that the PCR product for each subunit could be cleaved by a restriction endonuclease with a cleavage site unique to that product and yield at least one uniquely sized fragment (Table 1). Digestion of the $\alpha 2$ (BspD1), $\alpha 3$ (AvaI), and $\alpha 4$ (Aat2) products would yield fragments uniquely identifying $\alpha 2$ (348 bp), $\alpha 3$ (272 and $279 \mathrm{bp})$, and $\alpha 4$ (420 bp). Digestion of the $\beta 2$ (NheI) and $\beta 4$ ( $A f l 2)$ products would yield fragments uniquely identifying $\beta 2$ (474 bp) and $\beta 4$ (327 and $214 \mathrm{bp})$. The $\alpha 5$ (SalI) and $\beta 3$ (NcoI) products were digested separately, yielding uniquely identifying fragments for $\alpha 5$ (340 and $383 \mathrm{bp})$ and $\beta 3$ (219 and $236 \mathrm{bp}$ ). The $\alpha 7$ (Hae II) product digested to yield uniquely identifying fragments of 78 and $398 \mathrm{bp}$. The following factors - that the primers were designed specifically for neuronal nAChR subunit cDNAs, that enzymes were used that cleave at sites unique to each product, and that uniquely sized fragments were produced-render the possibility of false positives caused by primers annealing to cDNAs other than those encoding neuronal nAChR subunits as extremely unlikely.

\section{RESULTS}

\section{Parasympathetic intracardiac neurons display diverse whole-cell agonist pharmacologies}

To determine whether these neurons express a heterogeneous population of nicotinic receptors, we used the four agonists that were used in exogenous expression experiments (Luetje and Patrick, 1991). The rank order of potency, determined from the peak current amplitude in response to application of $100 \mu \mathrm{M}$ concentrations of $\mathrm{ACh}$, cytisine, nicotine, and DMPP, varied from cell to cell. Whole-cell current responses of two different neurons to agonist applications are shown in Figure $1 A$. The cell repre- sented in the top traces responded in the order cytisine $\geq \mathrm{ACh}>$ nicotine $>$ DMPP, whereas the cell in the bottom traces had a rank order potency of ACh $>$ DMPP $>$ cytisine $>$ nicotine. The whole-cell current amplitude evoked by cytisine, nicotine, and DMPP relative to that elicited by $\mathrm{ACh}$ is shown for 11 cells in Figure $1 B$. The neurons in Figure $1 B$ are plotted in the order of decreasing responsiveness to cytisine, with cell 1 having the largest response and cell 11 the smallest response, relative to $\mathrm{ACh}$. As we show, some of the cells shared the same pharmacological profile (i.e., cells 4 and 7 and cells 10 and 11). Each of the other neurons displayed a unique profile.

Our results in parasympathetic neurons differ from those obtained in oocyte expression experiments. The pharmacological profiles (agonist rank order of potency) of these neurons do not match the profiles of nicotinic receptors expressed in oocytes. In addition, these neurons display a greater number of rank orders of potency than have been observed in oocyte expression studies. There are several possible explanations for these differences. First, each individual neuron may express a distinct nAChR composed of a combination of subunits not previously characterized in exogenous expression studies. If this were true, then we would expect to see one receptor class in each neuron, with subunit expression varying from neuron to neuron. Second, each individual neuron may express the same combination of several different nAChRs, with differences in whole-cell pharmacology being attributable to individual neurons expressing different proportions of the same set of receptors. If this were true, then we would expect to see the same several receptor classes in each neuron, with subunit expression being the same in each neuron. Third, each individual neuron may express a different subset of a number of different $\mathrm{nAChR}$ classes, with differences in whole-cell pharmacology being attributable to the presence of different receptors. If this were true, we would expect to see different combinations of receptor classes in each neuron, with subunit expression varying from neuron to neuron. Fourth, these neurons may be expressing receptors containing subunits that have not yet been cloned. Investigation of this possibility is beyond the scope of this work. These possibilities are, of course, not mutually exclusive. However, by using biophysical techniques in excised outside-out patches and by examining the subunit mRNA expression patterns in individual neurons with RT-PCR, we have attempted to determine which of the first three possibilities most accurately describes the situation in these neurons.

\section{Multiple nAChR channel classes are expressed by parasympathetic intracardiac neurons}

We observed three distinct single-channel conductances in excised patches from rat intrinsic cardiac neurons. ACh-activated unitary currents were recorded from outside-out patches in response to application of $1 \mu \mathrm{M}$ ACh. Current amplitudes obtained at a holding potential of $-90 \mathrm{mV}$ ranged from $0.9-4.2 \mathrm{pA}$, corresponding to single-channel conductances of 10.0-46.6 pS. This range of conductances is much larger than would be expected for a single-channel class, consistent with the nicotinic receptors in these neurons being a population of heterogeneous channels.

ACh-activated single-channel currents exhibited more than one discrete amplitude level in all patches examined $(n=24)$. Singlechannel currents recorded from three excised membrane patches $(-90 \mathrm{mV})$ and the amplitude histograms obtained from the corresponding experimental records are shown in Figure $2 A, B$. Channel openings of at least two distinct amplitude levels are evident in the patch shown in Figure $2 \mathrm{Ai}$. These amplitude com- 
A
$\mathrm{ACh}$
Cytisine
Nicotine
DMPP
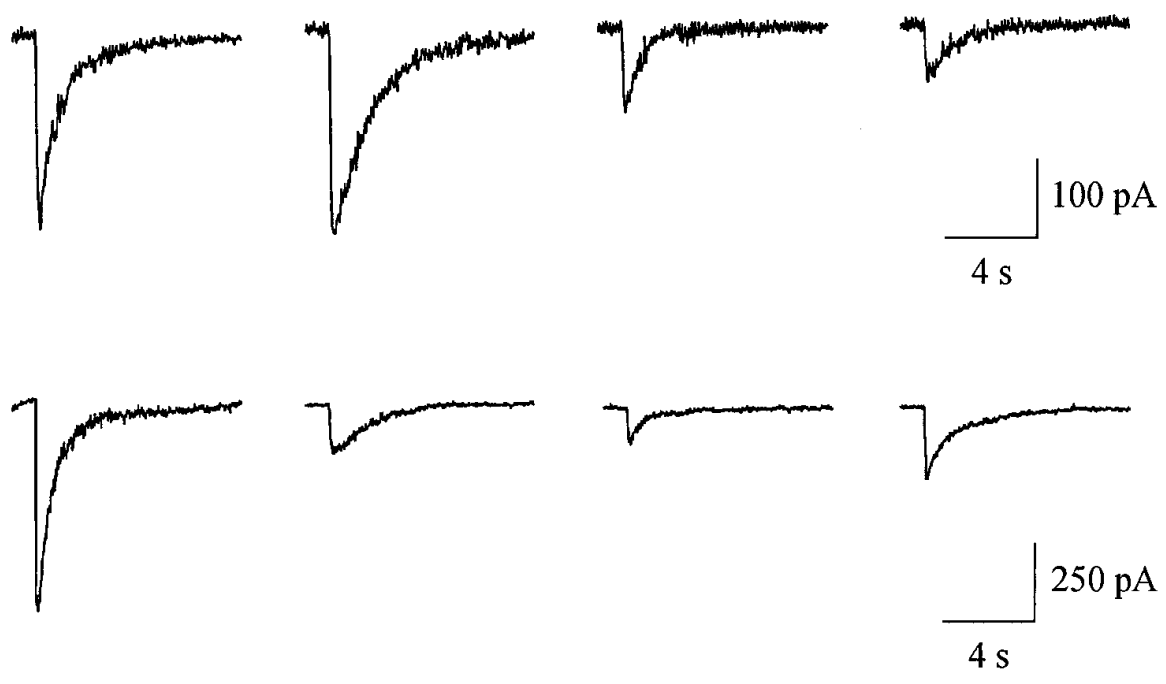

B

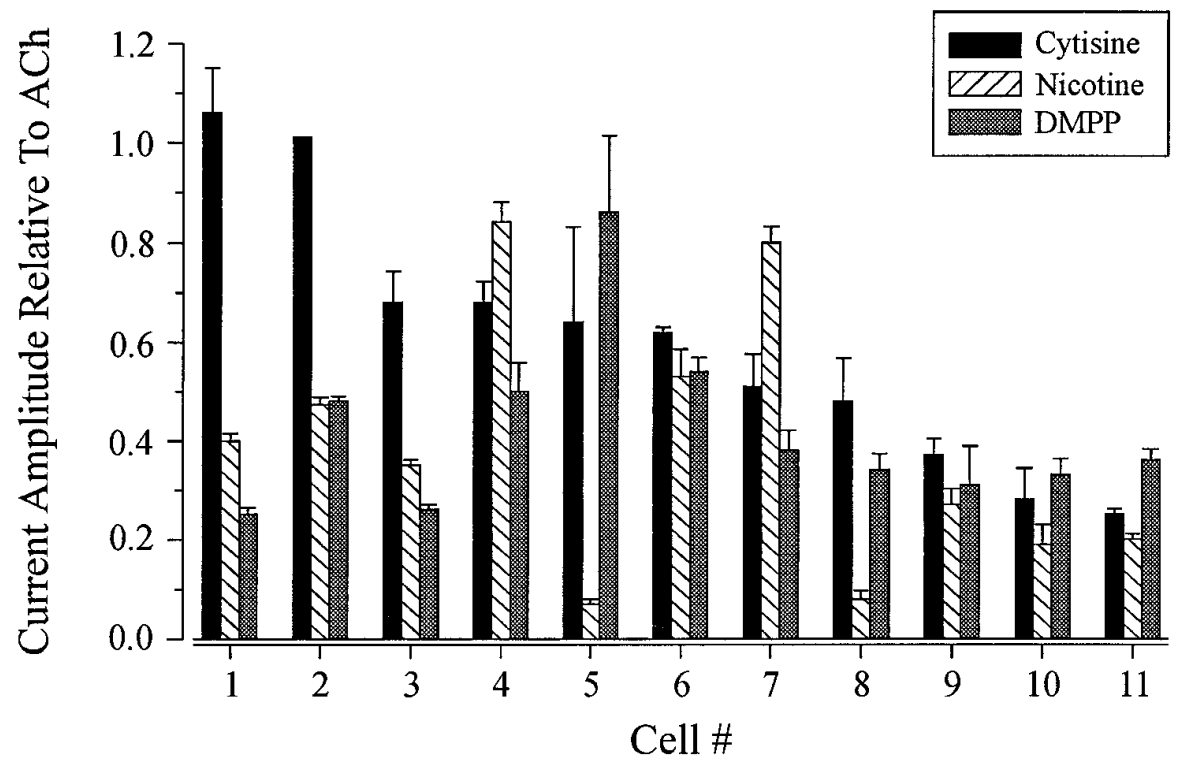

Figure 1. Whole-cell currents in rat parasympathetic neurons evoked by nicotinic agonists. $A$, Whole-cell current responses evoked by $10 \mathrm{msec}$ focal applications of 100 $\mu \mathrm{M}$ concentrations of $\mathrm{ACh}$, cytisine, nicotine, and DMPP in two different cells. Rank order of potency was determined by the peak current amplitude evoked by each agonist. One cell responded with a rank order of agonist potency of cytisine $\geq \mathrm{ACh}>$ nicotine $>$ DMPP (top current records), whereas the second cell responded in the order ACh $>$ DMPP $>$ cytisine $>$ nicotine (bottom current records). Holding potential, $-90 \mathrm{mV}$. $B$, Rank order of potency to nicotinic agonists in 11 parasympathetic intracardiac neurons. Current amplitude evoked by cytisine ( filled bars), nicotine (hatched bars), and DMPP (shaded bars) is plotted relative to ACh. Current records shown in $A$ correspond to cell 1 (top records) and cell 11 (bottom records). Cells are plotted in the order of decreasing response to cytisine. ponents correspond to mean single-channel conductances of $13.3 \pm 1.1 \mathrm{pS}$ for the small and $22.2 \pm 3.3 \mathrm{pS}$ for the large openings (Fig. $2 \mathrm{Bi}$ ). The patch represented in Figure $2 \mathrm{Aii}$ also contained two distinct conductance levels, with means of $24.4 \pm$ 2.2 and $34.4 \pm 3.3 \mathrm{pS}$ (Fig. 2Bii). Three distinct amplitude classes are observed in the patch shown in Figure 2Aiii, with conductances of $17.7 \pm 2.2 \mathrm{pS}$ for the small amplitude events, $24.4 \pm 1.1$ $\mathrm{pS}$ for the medium-sized events, and $30.0 \pm 2.2 \mathrm{pS}$ for the large amplitude events (Fig. 2Biii).

ACh-activated single-channel currents recorded from an excised outside-out patch at membrane potentials ranging from -90 $\mathrm{mV}$ to $+60 \mathrm{mV}$ are shown in Figure $3 A$. In this patch, three distinct current amplitude levels were observed and were most evident at the most negative or positive holding potentials. Channel openings were classified according to unitary current amplitude, and the single-channel current-voltage $(i-V)$ relation obtained from 16 different excised patches is shown in Figure $3 B$.
Three distinct levels of single-channel current amplitudes were observed, with linear $i-V$ relations and reversal potentials near 0 $\mathrm{mV}$ in symmetric $\mathrm{Na}^{+}$solutions. The $i-V$ relations for the three current levels were fit by linear regression and gave slope conductances of $18 \mathrm{pS}$ for the small current amplitude, $24 \mathrm{pS}$ for the medium-sized current, and $31 \mathrm{pS}$ for the large current amplitude. Linear single-channel $i-V$ relationships have been observed previously for the nAChRs in these neurons (Fieber and Adams, 1991; Adams and Nutter, 1992), as well as in rat sympathetic neurons (Mathie et al., 1991), whereas whole-cell nAChR $i-V$ curves can exhibit marked rectification (Mathie et al., 1990). We observed the small and medium conductances in $37.5 \%$ of patches (9 of 24), the medium and large in $25 \%$ of patches (6 of 24), and the small, medium, and large conductances in $37.5 \%$ of patches $(9$ of 24). Occasionally, larger amplitude openings were seen. The mean conductance of this channel, determined from 89 events in 10 different patches, was $39 \pm 2.6 \mathrm{pS}$. These results suggest that 
A

(i)

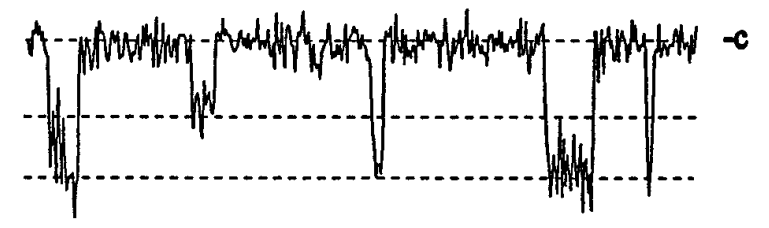

(ii)

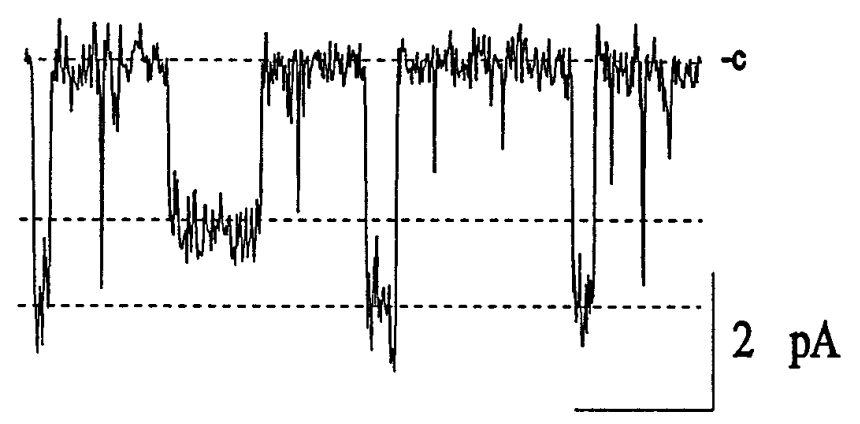

(iii)

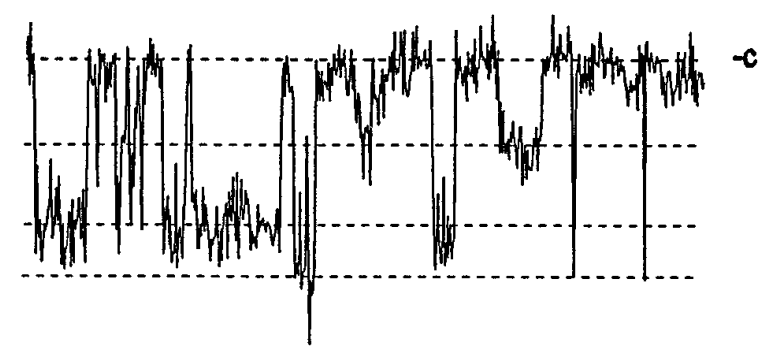

B

(i)

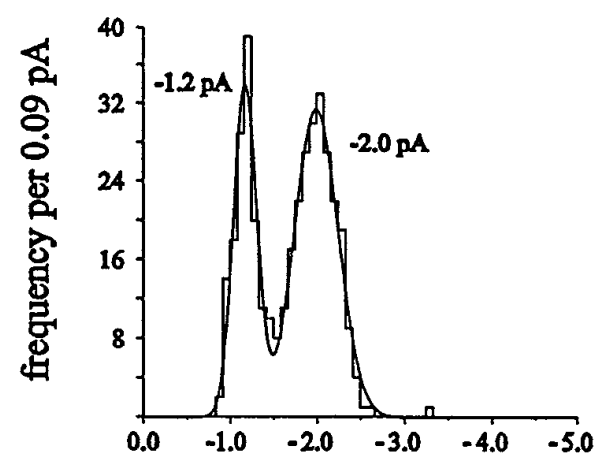

(ii)

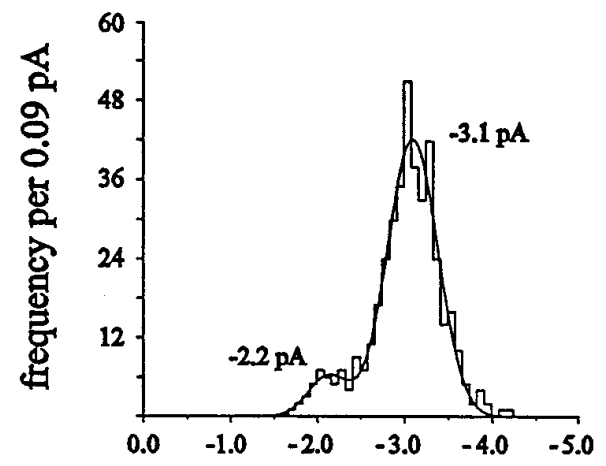

(iii)

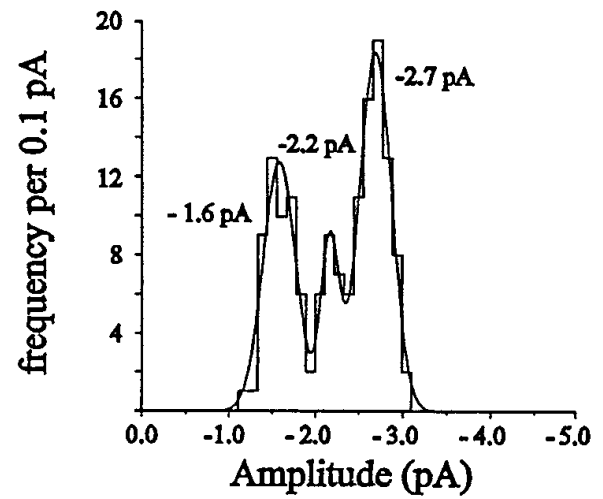

Figure 2. Interpatch variability of single-channel conductance levels activated by ACh. $A$, Unitary currents evoked by ACh in three separate outside-out membrane patches held at $-90 \mathrm{mV}$. Patches exhibited either the small and medium conductance ( $i, 9$ of 24 patches), the medium and large conductance (ii, 6 of 24 patches), or all three conductance levels (iii, 9 of 24 patches). Conductance levels are designated by the dashed lines, and the closed states of the channels are indicated. Currents were filtered at $3 \mathrm{kHz}$. $B$, Amplitude histograms of the experimental records from which the data shown in $A$ were taken. The current amplitude distributions are fit by Gaussian curves with mean \pm SD (relative area) of $(i)-1.2 \pm 0.1 \mathrm{pA}(37 \pm 3 \%)$ and $-2.0 \pm 0.3$ $\mathrm{pA}(63 \pm 4 \%),(i i)-2.2 \pm 0.2 \mathrm{pA}(13 \pm 4 \%)$ and $-3.1 \pm 0.3 \mathrm{pA}(87 \pm 4 \%)$, and (iii) $-1.6 \pm 0.2 \mathrm{pA}(36 \pm 3 \%),-2.2 \pm 0.1 \mathrm{pA}(14 \pm 3 \%)$, and $-2.7 \pm$ $0.2 \mathrm{pA}(50 \pm 4 \%)$.

these neurons express multiple nAChR classes and that individual neurons may express different combinations of receptors.

\section{Cultures of parasympathetic intracardiac neurons express a wide array of neuronal nAChR subunit mRNAs}

Data presented in Figures 1-3 suggest that these neurons express several distinct classes of $\mathrm{nAChR}$. To generate this pharmacological and biophysical diversity, these neurons may be expressing a large number of distinct $\mathrm{nAChR}$ subunits. To examine this possibility, we probed for $\mathrm{nAChR}$ subunit mRNA expression in cultures of parasympathetic intracardiac neurons by using RTPCR, followed by restriction digestion (Lambolez et al., 1992). PCR primers were designed to amplify products from neuronal nAChR subunit mRNAs encoding $\alpha 2, \alpha 3, \alpha 4, \alpha 5, \alpha 7, \beta 2, \beta 3$, and $\beta 4$ (see Table 1). The homology between subunit cDNA se- quences allowed design of three degenerate primer sets: one each for the $\alpha 2 / 3 / 4$ subunits, the $\beta 2 / 4$ subunits, and the $\alpha 5 / \beta 3$ subunits. The $\alpha 7$ primers were designed as a specific pair without degeneracy because of the minimal homology between this subunit and the others. The forward primers were placed at the $5^{\prime}$ end of the coding region, near the sequence encoding the cysteine loop. The reverse primers were placed within sequence-encoding transmembrane domains I and II. Use of PCR in these experiments raises several concerns that must be addressed: (1) the potential for false positives caused by contamination with cytoplasm from nearby cells or with nAChR subunit-encoding cDNAs used routinely in the laboratory, (2) genomic contamination, (3) primers annealing to untargeted cDNAs, (4) the potential that the degenerate primer pairs used to detect $\alpha 2 / 3 / 4, \beta 2 / 4$, or $\alpha 5 / \beta 3$ might be biased in favor of one subunit cDNA over others, or (5) potential 


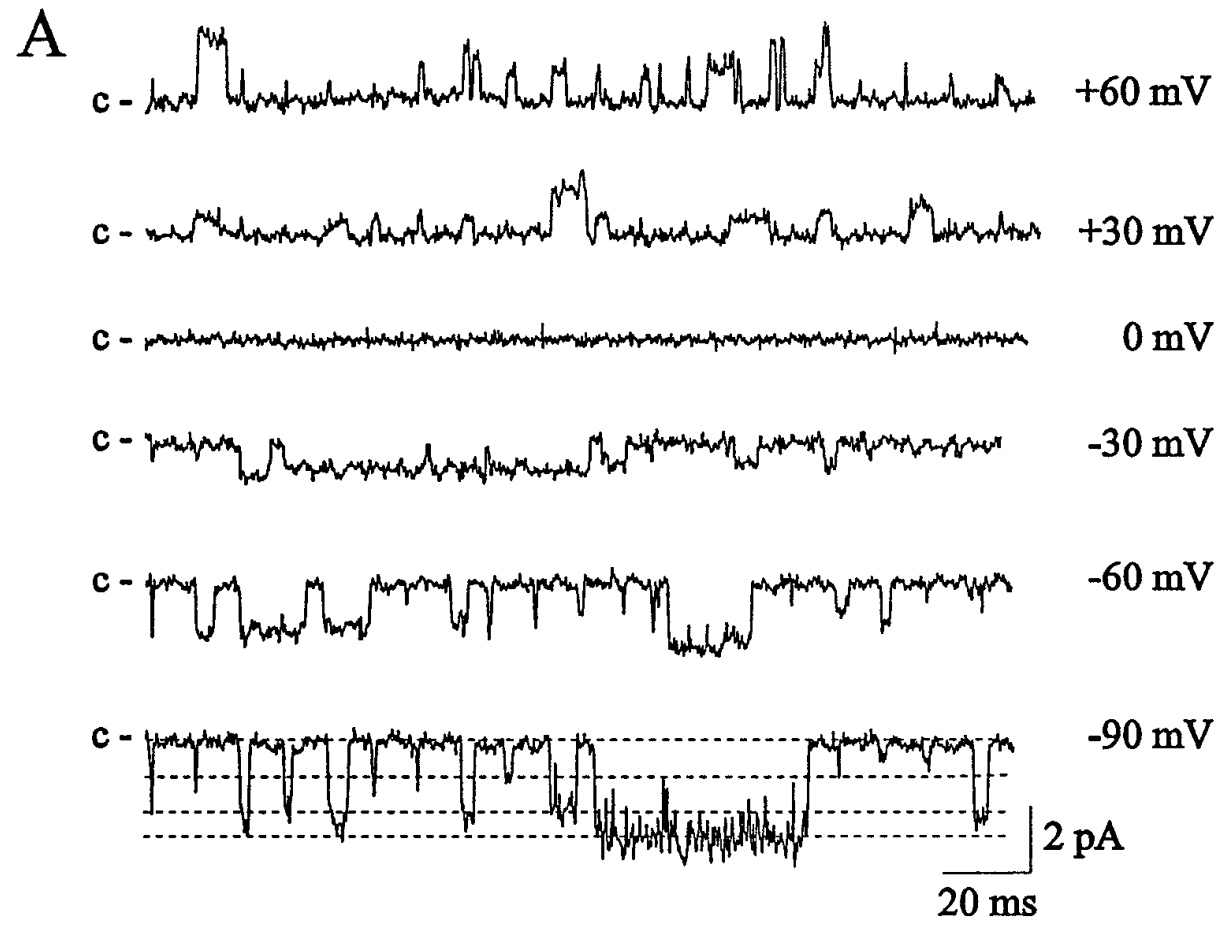

B

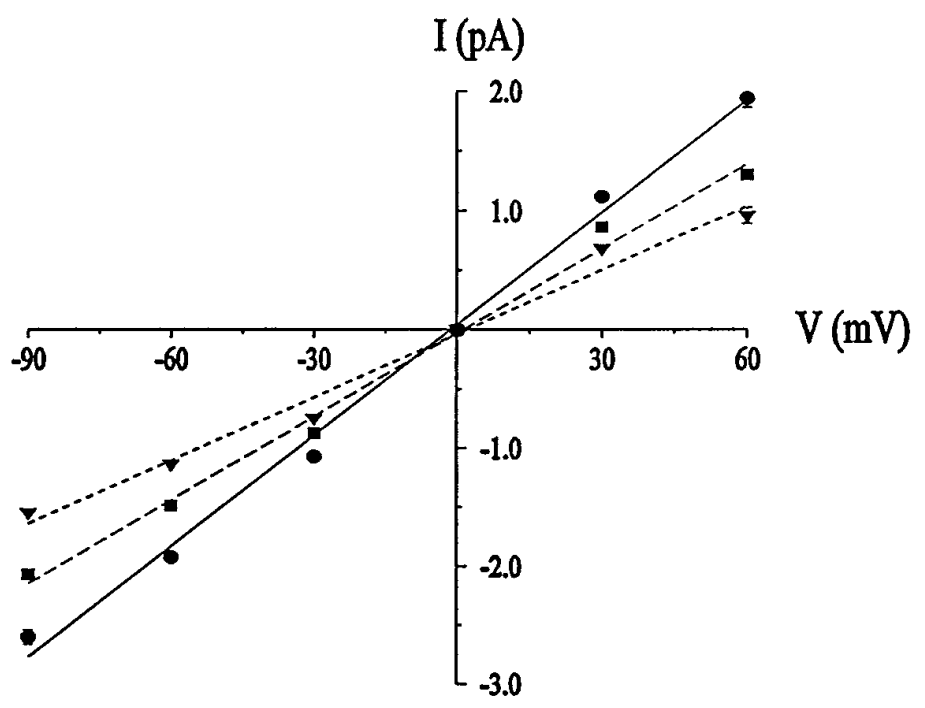

Figure 3. Single-channel currents evoked by exogenous ACh in rat cultured parasympathetic neurons. $A$, Unitary ACh-activated currents obtained in an excised outside-out membrane patch at the membrane potentials indicated. The closed states of the channels $(c)$ are indicated. Three distinct levels are evident in this patch (indicated by the dashed lines in the bottom trace), corresponding to slope conductances of $27.4,21.8$, and $16.6 \mathrm{pS}$. $B$, Current-voltage $(i-V)$ relations for single-channel currents activated by ACh. Each point represents the mean \pm SEM from 16 excised outside-out patches obtained from different cells, with $65-628$ openings per patch at each membrane potential. The data are fit by linear regression and give slope conductances of 18 pS (triangles), $24 \mathrm{pS}$ (squares), and $31 \mathrm{pS}$ (circles). Current records were filtered at $3 \mathrm{kHz}$ and digitized at $67 \mu \mathrm{sec} /$ point $(15 \mathrm{kHz})$. variability in our amplification protocol. These concerns were controlled for or ruled out, as described in Materials and Methods.

The primer bias issue is an important one and deserves attention here. We designed the degenerate primers by manipulating the primer sequence so that amplification of one subunit would not out-compete amplification of other subunits. Potential bias by degenerate primer pairs was tested directly by subjecting mixtures of cDNA templates encoding the target subunits to our PCR and restriction digestion protocol, followed by densitometric determination of the ratio of digested PCR products. A $\beta 2 / \beta 4$ template ratio of 1.0 (100 fg of each) yielded a PCR product ratio of 0.99 . $\beta 2 / \beta 4$ template ratios of 0.1 and 10.0 yielded PCR product ratios of 0.27 and 4.12 , respectively. The PCR product ratios are the mean of duplicate determinations, with individual values varying $<15 \%$ from the mean. These results demonstrate that the $\beta 2 / \beta 4$ primer set amplifies the $\beta 2$ and $\beta 4$ products without significant bias, although large differences between $\beta 2$ and $\beta 4$ products in our experiments may be underestimated. We performed a similar experiment for the $\alpha 2 / \alpha 3 / \alpha 4$ primer set. A template ratio of 1:1:1 (100 fg each) yielded a product ratio of 1.0:0.96:1.10. It should be noted that these bias control experiments are not directly comparable to the single-cell amplifications, which contain several orders of magnitude less starting material. Our control experiments do, however, allow us to rule out any gross bias in our primer sets.

As a test of our primers and the restriction digest strategy, we reverse-transcribed total RNA isolated from adult rat brain. We then subjected this cDNA to our PCR and digestion protocol (Fig. $4)$. The $\alpha 2 / 3 / 4$ product ( $A$, lane 2 ) digested to fragments diagnostic for $\alpha 2$ (348 bp), $\alpha 3$ (272 and $279 \mathrm{bp}$ ), and $\alpha 4$ (420 bp) (B, lane 2). The $\beta 2 / 4$ product ( $A$, lane 3$)$ digested to fragments diagnostic for $\beta 2$ (474 bp) and $\beta 4$ (214 and $327 \mathrm{bp})$ (B, lane 3$)$. In this experi- 
A

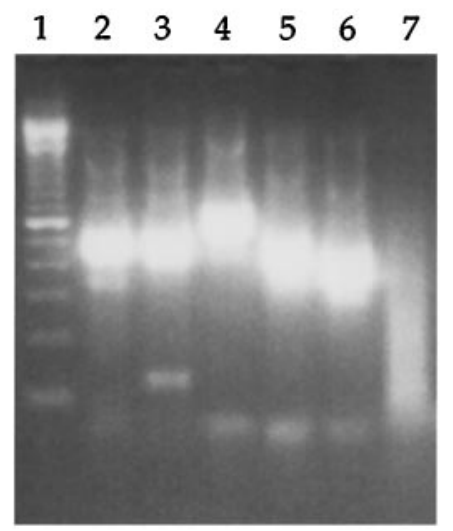

B

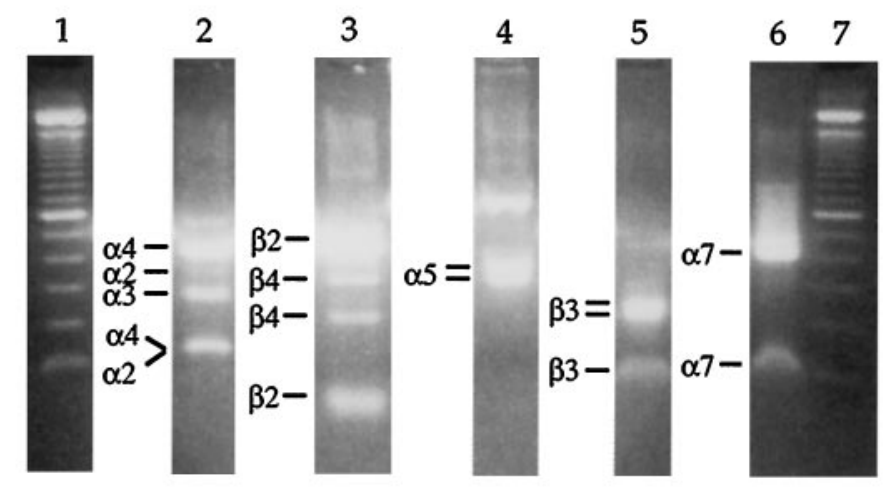

Figure 4. RT-PCR identification of mRNA encoding $\alpha 2, \alpha 3, \alpha 4, \alpha 5, \alpha 7, \beta 2, \beta 3$, and $\beta 4$ in rat brain RNA. A, Second-round PCR products. Lane 1, 100 bp standards; lanes $2-6$ are the PCR products amplified with the $\alpha 2 / 3 / 4, \beta 2 / 4, \alpha 5, \beta 3$, and $\alpha 7$ primers, respectively. In this experiment, $\alpha 5$ and $\beta 3$ were amplified separately. Lane 7 is the negative control. B, Restriction digestion of PCR products. Lanes 1, 7, 100 bp standards; lanes $2-6$ contain digested second-round PCR products for $\alpha 2 / 3 / 4, \beta 2 / 4, \alpha 5, \beta 3$, and $\alpha 7$ primers, respectively. Fragments identifying each subunit are labeled to the left of each lane. For enzymes used and exact fragment sizes, see Table 2 . For clarity in presentation, we have removed the undigested sample routinely run next to each digested product.

A

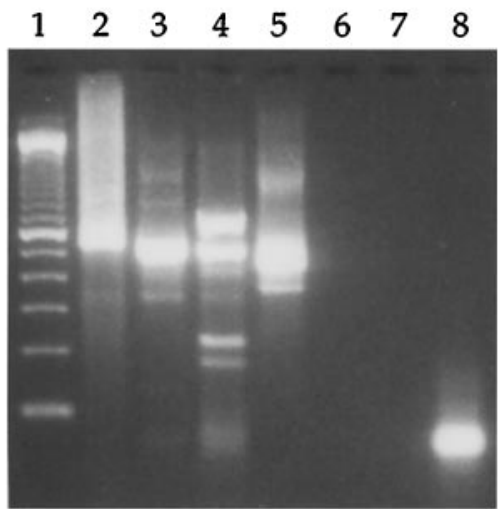

B

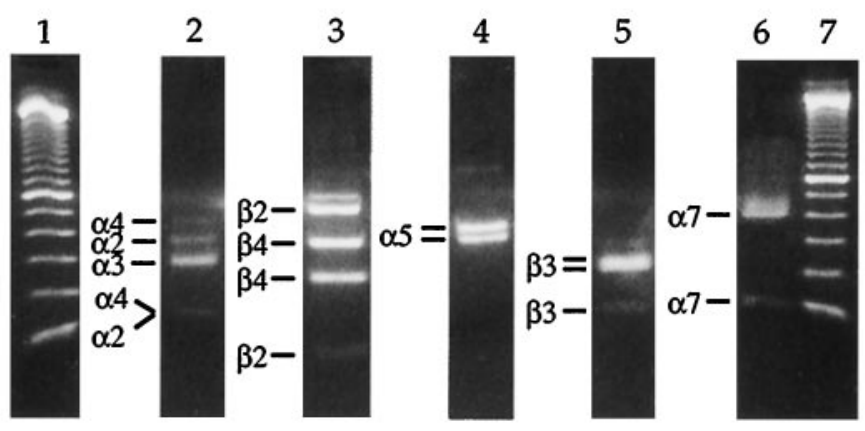

Figure 5. Neuronal nicotinic receptor subunit mRNAs encoding $\alpha 2, \alpha 3, \alpha 4, \alpha 5, \alpha 7, \beta 2, \beta 3$, and $\beta 4$ are expressed by cultures of intracardiac parasympathetic neurons. $A$, Second-round PCR products. Lane 1, $100 \mathrm{bp}$ standards; lanes $2-5$ are the PCR products obtained by using the $\alpha 2 / 3 / 4, \beta 2 / 4$, $\alpha 5 / \beta 3$, and $\alpha 7$ primers, respectively. In this experiment, $\alpha 5$ and $\beta 3$ products were amplified in the same reaction (lane 4 ). Lanes 6 and 7 are blank. Lane 8 is the negative control. $B$, Restriction digestion of PCR products. Lanes 1, 7, 100 bp standards; lanes $2-6$ contain the digested fragments for the $\alpha 2 / 3 / 4$, $\beta 2 / 4, \alpha 5, \beta 3$, and $\alpha 7$ products, respectively. Note that the $\alpha 5$ and $\beta 3$ products, although amplified in the same reaction, are digested separately because of different buffer requirements. Fragments identifying each subunit are labeled to the left of each lane. For enzymes used and exact fragment sizes, see Table 1. For clarity in presentation, we have removed the undigested sample routinely run next to each digested product.

ment, the $\alpha 5$ and $\beta 3$ products were amplified separately, using the degenerate forward primer and specific reverse primer for each. The $\alpha 5$ product $(A$, lane 4$)$ digested to fragments diagnostic for $\alpha 5$ (340 and $383 \mathrm{bp)}(B$, lane 4$)$. The $\beta 3$ product $(A$, lane 5$)$ digested to fragments diagnostic for $\beta 3$ (219 and $236 \mathrm{bp}$ ) (B, lane 5$)$. The $\alpha 7$ product ( $A$, lane 6 ) digested to a fragment diagnostic for $\alpha 7$ (398 bp) (B, lane 6). No products were amplified in the negative control (A, lane 7$)$.

Next we examined the expression of neuronal nAChR subunit mRNAs by a dish of cultured parasympathetic intracardiac neurons. At $3 \mathrm{~d}$ after dissociation, this culture contained $\sim 100$ neurons as well as a number of other cell types (e.g., cardiac myocytes, Schwann cells, and fibroblasts). Total RNA extracted from this sample was reverse-transcribed and subjected to our PCR and digestion protocol (Fig. 5). We found that RNA encoding each of the subunits for which we probed $(\alpha 2, \alpha 3, \alpha 4, \alpha 5, \alpha 7, \beta 2, \beta 3$, and $\beta 4)$ was expressed by this dish of cultured neurons. There are several possible explanations for this result. First, each neuron may be expressing the same wide array of subunit mRNAs, a result that would be consistent with the idea that each neuron expresses the same receptor classes, but the proportions of each class vary from neuron to neuron. Second, different neurons may be expressing different combinations of subunit mRNAs, which would be consistent with the hypothesis that individual neurons may assemble different combinations of receptor classes. Third, the neurons may be expressing only a subset of the observed subunit mRNAs, with the rest being expressed by other cell types on the dish. To distinguish among these possibilities, we used the RT-PCR and digestion strategy to examine the expression of subunit mRNAs by individual neurons. 


\section{Individual parasympathetic intracardiac neurons differ in their neuronal nAChR subunit mRNA expression patterns}

To examine the subunit mRNA expression patterns of individual neurons, we isolated the cytosolic contents of each neuron by aspiration with a patch pipette in the whole-cell configuration. Then the contents of each neuron were subjected to a reverse transcription reaction, followed by our PCR and restriction digest protocol. The results for several neurons are shown in Figure 6 . Results obtained for these and additional neurons are presented in Table 2 .

The nAChR subunit mRNA expression patterns among individual neurons are diverse. Neuron A (Fig. $6 A$ ) expresses mRNA encoding $\alpha 2, \alpha 3, \alpha 4, \alpha 7$, and $\beta 2$. Neuron B (Fig. 6B) expresses mRNA encoding $\alpha 3, \alpha 5$, and $\beta 4$. Neuron $\mathrm{C}$ (Fig. 6C) expresses mRNA encoding $\alpha 3, \alpha 5, \alpha 7$, and $\beta 2$. Neuron D (Fig. 6D) expresses $\alpha 3, \alpha 4, \beta 3$, and $\beta 4$. Neuron $\mathrm{E}$ (Fig. $6 E$ ) expresses $\alpha 3, \alpha 5$, and $\beta 2$. Neurons $C$ and $D$ were dissected from the same rat and cultured on the same dish, demonstrating that the differences in mRNA expression are not attributable to differences in culture conditions or "inter-rat" variability. Similarly, three neurons isolated from another heart, cultured together in the same dish and probed for $\beta 2$ and $\beta 4$ mRNA expression, also were found to differ (data not shown). Although the nAChR subunit mRNA expression patterns of individual neurons are quite diverse, all neurons were similar in two respects. First, all of the neurons express mRNA encoding the $\alpha 3$ subunit, consistent with numerous observations of the expression of this subunit in peripheral neurons (Boyd et al., 1988; Listerud et al., 1991; Rust et al., 1994). Second, all of the neurons express mRNA encoding either or both the $\beta 2$ or $\beta 4$ subunits. Thus, expression of $\alpha 3$ and $\beta 2$ and/or $\beta 4$ may be ubiquitous in intrinsic cardiac neurons. The expression patterns for the other subunit mRNAs were diverse, varying from neuron to neuron. Each of the subunit mRNAs shown to be present in RNA isolated from an entire dish of neurons (Fig. 5) is expressed by at least one of the neurons we have examined individually (Fig. 6 and Table 2). Thus, the subunit mRNA expression by neurons can account for all of the subunit mRNA expression seen at the dish level and supports the hypothesis of heterogeneous expression of nAChRs among individual neurons.

\section{DISCUSSION}

Our results show that individual parasympathetic neurons of neonatal rat intracardiac ganglia express a heterogeneous population of nAChR subunits. At the whole-cell level, the rank order of potency of several nicotinic agonists varied among individual neurons. Single-channel recordings demonstrate the presence of at least three distinct conductance classes $(18,24$, and $31 \mathrm{pS})$. When the expression of $\mathrm{nAChR}$ subunit mRNAs was examined by RT-PCR, these cultures of neurons were found to express a wide array of subunit mRNAs $(\alpha 2, \alpha 3, \alpha 4, \alpha 5, \alpha 7, \beta 2, \beta 3$, and $\beta 4)$. At the single-cell level, RT-PCR demonstrated that individual neurons expressed distinctly different arrays of nAChR subunit mRNAs. These results are consistent with the hypothesis that individual neurons in this preparation express distinct subsets of several different nAChR classes.

When we examined the whole-cell agonist pharmacology of rat intracardiac neurons, we observed a greater number of rank orders of potency than seen in exogenous expression of $\mathrm{nAChR}$ subunit mRNAs, and none of the profiles in neurons matched those in oocytes (Fig. 1B). The dissimilarities of the profiles between neurons and oocytes suggest a greater degree of heter- ogeneity of subunit expression in neurons than the pairwise or homomeric expression of subunits in oocytes. However, exogenous expression data provide useful observations. For example, in oocyte expression experiments both the $\alpha$ and $\beta$ subunits contribute to the pharmacological profile of neuronal nAChRs (Luetje and Patrick, 1991). Responsiveness to cytisine seems to be influenced primarily by the identity of the $\beta$ subunit, because nAChRs containing $\beta 4$ are several-fold more sensitive to cytisine than to $\mathrm{ACh}$, whereas those containing $\beta 2$ are many-fold less sensitive to cytisine than to ACh. The cell-to-cell variation in the cytisineevoked responses in the present study (Fig. 1) could, therefore, reflect differing ratios of $\beta 2$ and $\beta 4$ subunits, with cell 1 containing a higher proportion of $\mathrm{nAChR}$ channels composed of $\beta 4$ subunits and cell 11 having channels containing primarily $\beta 2$ subunits. Similarly, intracardiac parasympathetic neurons expressing varying ratios of $\mathrm{nAChR}$ receptors composed of different combinations of $\alpha$ and $\beta$ subunits could account for the diversity observed for the other agonists.

Our single-channel experiments, conducted on outside-out membrane patches, yielded results consistent with the presence of at least three different conductance levels for $\mathrm{nAChR}$ channels in rat intracardiac neurons. The consistent expression of $\alpha 3$ mRNA in every neuron examined and the presence of the medium conductance in every patch suggest that the $\mathrm{nAChR}$ responsible for the medium conductance contains $\alpha 3$. The expression of multiple neuronal nicotinic ACh receptors also has been studied in thin slices of rat medial habenula via patch-clamp techniques (Connolly et al., 1995). The heterogeneity of nAChRs in cells of this preparation was suggested by the presence of at least two singlechannel conductances (51 and $41 \mathrm{pS}$ ) with distinct open times. Detailed analysis concluded that these conductance classes were produced by two molecularly distinct nAChR subtypes. In contrast to our findings, although rat superior cervical ganglion (SCG) neurons express five nAChR transcripts $(\alpha 3, \alpha 5, \alpha 7, \beta 2$, and $\beta 4$ ), Mandelzys et al. (1995) used pharmacological analysis to suggest that the nAChRs on these neurons are a uniform population.

To begin to understand the molecular basis for the pharmacological and biophysical diversity that we have observed, we adapted the RT-PCR strategy of Lambolez et al. (1992) for neuronal $\mathrm{nAChR}$ subunits. We found that individual intracardiac parasympathetic neurons express distinct subsets of nAChR subunit mRNAs. The subunit mRNA expression pattern of individual neurons ranged from simple to complex (e.g., in Table 2, compare neuron $\mathrm{F}$, expressing $\alpha 3$ and $\beta 4$, with neuron $\mathrm{A}$, expressing $\alpha 2, \alpha 3$, $\alpha 4, \alpha 7$, and $\beta 2$ ). Differences in $\mathrm{nAChR}$ subunit expression resulting from differential mRNA expression, then, may account for the observed variability in both whole-cell pharmacology and singlechannel conductance. It is important to note that protein levels do not necessarily parallel mRNA levels. Thus differential translation, protein stability, or receptor assembly could provide additional levels of regulation. Although it is possible that the heterogeneity we observe might be generated artifactually as a result of studying these neurons in culture, the results of Connolly et al. (1995), as noted above, suggest that this diversity also occurs in vivo. Also, Ullian and Sargent (1995) used subunit-specific monoclonal antibodies to identify at least five distinct classes of neurons in the chick lateral spiriform nucleus on the basis of differential expression of $\mathrm{nAChR}$ subunits. These reports, together with our findings, indicate that the classification of nAChRs in neurons will not be a simple task.

Our analysis of nAChR subunit mRNA expression patterns in 
$\begin{array}{llllll}1 & 2 & 3 & 4 & 5 & 6\end{array}$

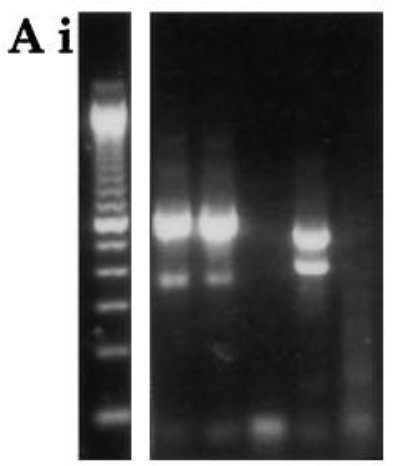

$\begin{array}{lllll}1 & 2 & 3 & 4 & 5\end{array}$

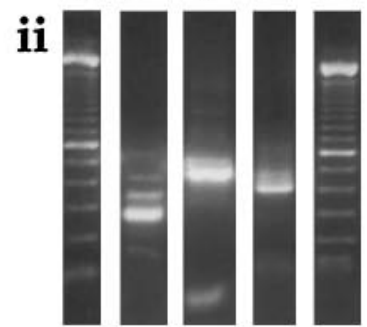

$\begin{array}{lllllll}1 & 2 & 3 & 4 & 5 & 6 & 7\end{array}$

B i
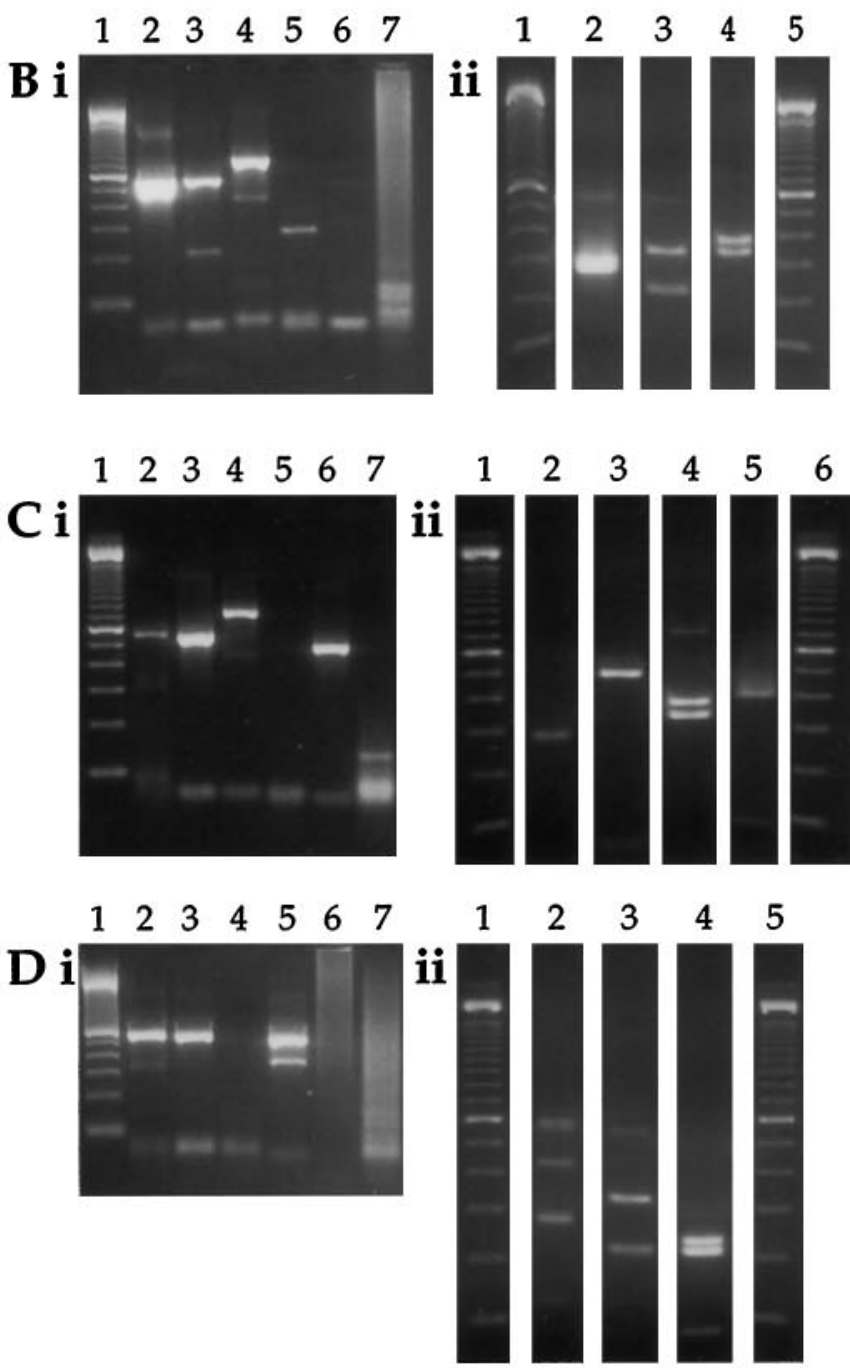

1
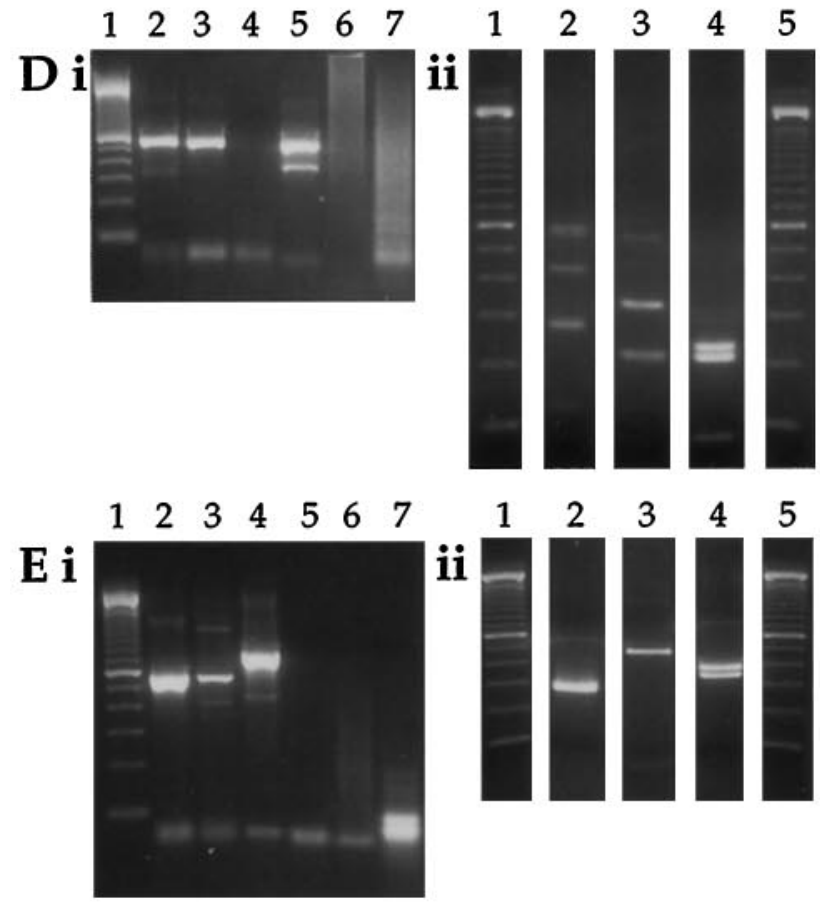

individual neurons relies on the use of the PCR technique, raising several concerns. We describe our controls in detail in Materials and Methods, but two issues deserve discussion here. One potential problem is that there may be an intrinsic bias within our degenerate primer sets that favors one subunit mRNA over another. The evidence suggesting a lack of bias in the $\beta 2 / 4$ primer pair is discussed at length in Results. For the $\alpha 5 / \beta 3$ primer set, one or the other of these PCR products does not predominate consistently in our results, and in many of our experiments we probed for the two subunits in separate reactions. Bias conceivably could be a problem with the $\alpha 2 / 3 / 4$ primer set, because the $\alpha 3$ product does predominate consistently in our experiments. We can argue against this possibility in two ways. First, although $\alpha 3$ is predominant in all of the cells tested individually (Fig. 6 and Table 2 ) as well as in dishes of neurons (Fig. 5), the $\alpha 4$ PCR product predominates over the $\alpha 2$ and $\alpha 3$ products when we probe rat brain RNA (Fig. 4), consistent with the known predominance of $\alpha 4$ mRNA in rat brain. Second, similar to the $\beta 2 / 4$ pair, in control experiments we have demonstrated a lack of bias in the $\alpha 2 / 3 / 4$ primer set. Thus, when one degenerate primer set is used in a single reaction, differences in levels of products are likely to be an approximate reflection of differences in levels of mRNA transcripts in the cells. A second concern is the sensitivity of our methods when we are working at the single-cell level. Failure to detect transcripts encoding a particular subunit simply may reflect a level of subunit mRNA expression below our threshold level of detection. Because the reverse-transcribed cytoplasm is split into four or five PCR reactions, we are attempting to detect subunit mRNAs in less than a single cytoplasm. We have been unable to devise an appropriate and feasible control for this, and so expression of subunit mRNAs below our level of detection remains a possibility.

Pharmacological analysis and single-cell RT-PCR performed on the same neuron proved problematic in this study. We believe this is attributable to the extended length of time required to obtain a full pharmacological profile for each neuron. These experiments typically took $30-45 \mathrm{~min}$ to complete, during which time the RNA in the cell had ample opportunity for degradation. In any event, it seems that the length of time required by the electrophysiological recordings ruined the chance of success for the PCR. The use of a noninvasive technology (e.g., $\mathrm{Ca}^{2+}$ fluorescence imaging) is being explored for pharmacological analysis in future experiments.

An intriguing issue is the potential importance that heterogeneous expression of neuronal nAChRs may have in the control of cardiac function. Mammalian epicardial ganglionated plexi are composed of different types of neurons, including both cholinergic

Figure 6. Individual intracardiac parasympathetic neurons express diverse arrays of nAChR subunit mRNAs. Second-round PCR $(i)$ and restriction digestion (ii) results for neurons A-E are shown. $A$, Neuron expressing $\alpha 2$, $\alpha 3$, and $\alpha 4$ (lanes $2 i$ and 2ii), $\alpha 7$ (lanes $5 i$ and $4 i i$ ), and $\beta 2$ (lanes $3 i$ and $3 i i)$. $B$, Neuron expressing $\alpha 3$ (lanes $2 i$ and $2 i i$ ), $\alpha 5$ (lanes $4 i$ and $4 i i$ ), and $\beta 4$ (lanes $3 i$ and $3 i i$ ). $C$, Neuron expressing $\alpha 3$ (lanes $2 i$ and 2ii), $\alpha 5$ (lanes $4 i$ and $4 i i), \alpha 7$ (lanes $6 i$ and 5ii), and $\beta 2$ (lanes $3 i$ and $3 i i)$. D, Neuron expressing $\alpha 3$ and $\alpha 4$ (lanes $2 i$ and $2 i i), \beta 3$ (lanes $5 i$ and $4 i i)$, and $\beta 4$ (lanes $3 i$ and $3 i i)$. E, Neuron expressing $\alpha 3$ (lanes $2 i$ and $2 i i$ ), $\alpha 5$ (lanes $4 i$ and 4ii), and $\beta 2$ (lanes $3 i$ and $3 i i$ ). Neurons $\mathrm{C}$ and D were harvested from the same culture dish. Negative controls are run in lane 6 for neuron A and lane 7 for neurons B-E. $100 \mathrm{bp}$ size standards are run in lane 1 of each second-round PCR gel ( $\mathrm{Ai}-\mathrm{Ei})$; lanes 1 and 5 in Aii, Bii, Dii, and Eii; and lanes 1 and 5 in Cii. For clarity in presentation, we have removed the lanes containing undigested samples routinely run next to each digested product. 


Table 2. Expression of nAChR subunit mRNAs among individual
intracardiac parasympathetic neurons
\begin{tabular}{llllllllll} 
Neuron & $\alpha 2$ & $\alpha 3$ & $\alpha 4$ & $\alpha 5$ & $\alpha 7$ & $\beta 2$ & $\beta 3$ & $\beta 4$ \\
\hline A & + & + & + & & + & + & & \\
B & & + & & + & & & & + \\
C & & + & & + & + & + & & \\
D & & + & + & & & & + & + \\
E & & + & & + & & + & & \\
F & & + & & & & & & + \\
G & & + & & & + & & + & + \\
H & & + & & & + & + & & \\
I & + & & & + & + & & + \\
\hline
\end{tabular}

and adrenergic postganglionic efferents, interneurons, and afferent neurons (Moravec and Moravec, 1987; Armour, 1991; Ardell, 1994). Although ACh is the principal neurotransmitter found in the vagal efferent fibers and the epicardial parasympathetic ganglia (Jacobowitz, 1967; Ehinger et al., 1968; Seabrook et al., 1990), numerous putative neurotransmitters and neuromodulators have been detected within intracardiac ganglia by the use of immunohistochemical techniques (Allen et al., 1994; Steele et al., 1994, 1996). In addition to this molecular complexity, the functional properties of intrinsic cardiac ganglia differ in different regions of the mammalian heart. For example, neurons in the right atrial ganglionated plexus control the sinoatrial node (Butler et al., 1990). The inferior vena cava-inferior atrial plexus modulates the atrioventricular node (Ardell and Randall, 1986). The dorsal atrial and the cranial medial ventricular ganglia modulate contractile tissue (Yuan et al., 1994). Our results demonstrate that individual intracardiac neurons differ in their $\mathrm{nAChR}$ expression. Calcium permeability differs among neuronal nAChRs, depending on subunit composition, and thus intracellular calcium levels and neuronal excitability may be affected to differing extents. Neuronal nAChRs also can be differentially localized on neuronal surfaces (Wilson Horch and Sargent, 1996). This differential localization may be determined by subunit composition and could be involved in reception of multiple inputs. Thus, heterogeneous expression of nAChRs by intracardiac neurons is likely to have a profound influence on neural control of cardiac function.

\section{REFERENCES}

Adams DJ, Nutter TJ (1992) Calcium permeability and modulation of nicotinic acetylcholine receptor channels in rat parasympathetic neurons. J Physiol (Paris) 86:67-76.

Allen TGJ, Hassall CJS, Burnstock G (1994) Mammalian intrinsic cardiac neurons in cell culture. In: Neurocardiology (Armour JA, Ardell JL, eds), pp 115-138. New York: Oxford UP.

Anand R, Conroy WG, Schoepfer R, Whiting P, Lindstrom J (1991) Neuronal nicotinic acetylcholine receptors expressed in Xenopus oocytes have a pentameric quarternary structure. J Biol Chem 266:11192-11198.

Ardell JL (1994) Structure and function of mammalian intrinsic cardiac neurons. In: Neurocardiology (Armour JA, Ardell JL, eds), pp 95-114. New York: Oxford UP.

Ardell JL, Randall WC (1986) Selective vagal innervation of sinoatrial and atrioventricular nodes in canine hearts. Am J Physiol 251:H764-H773.

Armour JA (1991) Intrinsic cardiac neurons. J Cardiovasc Electrophysiol 2:331-341.

Boulter J, Connolly J, Deneris E, Goldman D, Heinemann S, Patrick J (1987) Functional expression of two neuronal nicotinic acetylcholine receptors from cDNA clones identifies a gene family. Proc Natl Acad Sci USA 84:7763-7767.

Boyd RT, Jacob MH, Couturier S, Ballivet M, Berg DK (1988) Expres- sion and regulation of neuronal acetylcholine receptor mRNA in chick ciliary ganglia. Neuron 1:495-502.

Butler CK, Smith FM, Cardinal R, Murphy DA, Hopkins DA, Armour JA (1990) Cardiac responses to electrical stimulation of discrete loci in canine atrial and ventricular ganglionated plexi. Am J Physiol (Heart Circ Physiol 28) 259:H1108-H1117.

Chomczynski P, Sacchi N (1987) Single-step method of RNA isolation by acid-guanidinium-thiocyanate-phenol-chloroform extraction. Anal Biochem 162:156-159.

Colquhoun L, Dineley K, Patrick J (1993) A hetero-beta neuronal nicotinic acetylcholine receptor expressed in Xenopus oocytes. Soc Neurosci Abstr 19:1533.

Connolly JG, Gibb AJ, Colquhoun D (1995) Heterogeneity of neuronal nicotinic acetylcholine receptors in thin slices of rat medial habenula. J Physiol (Lond) 484:87-105.

Cooper E, Couturier S, Ballivet M (1991) Pentameric structure and subunit stoichiometry of a neuronal nicotinic acetylcholine receptor. Nature 350:235-238.

Covernton PJO, Kojima H, Sivilotti LG, Gibb AJ, Colquhoun D (1994) Comparison of neuronal nicotinic receptors in rat sympathetic neurones with subunit pairs expressed in Xenopus oocytes. J Physiol (Lond) 481:27-34.

Duvoisin RM, Deneris ES, Boulter J, Patrick J, Heinemann S (1989) The functional diversity of the neuronal nicotinic acetylcholine receptors is increased by a novel subunit: $\beta 4$. Neuron 3:487-496.

Ehinger B, Falck B, Persson H, Sporrono B (1968) Adrenergic and cholinesterase-containing neurons of the heart. Histochimie 16:197-205.

Elgoyhen AB, Johnson DS, Boulter J, Vetter DE, Heinemann S (1994) $\alpha 9$ : an acetylcholine receptor with novel pharmacological properties expressed in rat cochlear hair cells. Cell 79:705-715.

Fieber LA, Adams DJ (1991) Acetylcholine-evoked currents in cultured neurones dissociated from rat parasympathetic cardiac ganglia. J Physiol (Lond) 434:215-237.

Flores CM, Rogers SW, Pabreza LA, Wolfe BB, Kellar KJ (1991) A subtype of nicotinic cholinergic receptor in rat brain is composed of $\alpha 4$ and $\beta 2$ subunits and is up-regulated by chronic nicotine treatment. Mol Pharmacol 41:31-37.

Forsayeth JR, Kobrin E, Winegar BD, Fitzgerald DJ (1995) The nicotinic acetylcholine receptor in cerebellum is composed of four different subunits. Soc Neurosci Abstr 21:1583.

Hamill OP, Marty A, Neher E, Sakmann B, Sigworth F (1981) Improved patch-clamp techniques for high resolution current recordings from cells and cell-free membrane patches. Pflügers Arch 391:85-100.

Jacobowitz D (1967) Histochemical studies of the relationship of chromaffin cell and adrenergic nerve fibers to the cardiac ganglia of several species. J Pharmacol Exp Ther 158:227-240.

Lambolez B, Audinat A, Bochet P, Crépel F, Rossier J (1992) AMPA receptor subunits expressed by single Purkinje cells. Neuron 9:247-258.

Listerud M, Brussaard AB, Devay P, Colman DR, Role LW (1991) Functional contribution of neuronal AChR subunits revealed by antisense oligonucleotides. Science 254:1518-1521.

Luetje CW, Wada K, Rogers S, Abramson SN, Tsuji K, Heinemann S, Patrick J (1990) Neurotoxins distinguish between different neuronal nicotinic acetylcholine receptor subunit combinations. J Neurochem 55:632-640.

Luetje CW, Patrick J (1991) Both $\alpha$ - and $\beta$-subunits contribute to the agonist sensitivity of neuronal nicotinic acetylcholine receptors. J Neurosci 11:837-845.

Mandelzys A, de Koninck P, Cooper E (1995) Agonist and toxin sensitivities of ACh-evoked currents on neurons expressing multiple nicotinic ACh receptor subunits. J Neurophysiol 74:1212-1221.

Mathie A, Colquhoun D, Cull-Candy SG (1990) Rectification of currents activated by nicotinic acetylcholine receptors in rat sympathetic ganglion neurones. J Physiol (Lond) 427:625-655.

Mathie A, Cull-Candy SG, Colquhoun D (1991) Conductance and kinetic properties of single nicotinic acetylcholine receptors channels in rat sympathetic neurones. J Physiol (Lond) 439:717-750.

Moravec J, Moravec M (1987) Intrinsic nerve plexus of mammalian heart: morphological basis of cardiac rhythmical activity? Int Rev Cytol 106:89-147.

Moss BL, Role LW (1993) Enhanced ACh sensitivity is accompanied by changes in ACh receptor channel properties and segregation of ACh receptor subtypes on sympathetic neurons during innervation in vivo. J Neurosci 13:13-28. 
Papke RL, Heinemann SF (1991) The role of the beta 4 subunit in determining the kinetic properties of rat neuronal nicotinic acetylcholine alpha 3 receptors. J Physiol (Lond) 440:95-112.

Papke RL, Boulter J, Patrick J, Heinemann SF (1989) Single-channel currents of rat neuronal nicotinic acetylcholine receptors expressed in Xenopus oocytes. Neuron 3:589-596.

Ramirez-Latorre J, Yu CR, Qu X, Perin F, Karlin A, Role L (1996) Functional contributions to $\alpha 5$ subunit to neuronal acetylcholine receptor channels. Nature 380:347-351.

Rust G, Burgunder J-M, Lauterberg TE, Cachelin AB (1994) Expression of neuronal nicotinic acetylcholine receptor subunit genes in the rat autonomic nervous system. Eur J Neurosci 6:478-485.

Sargent PB (1993) The diversity of neuronal nicotinic acetylcholine receptors. Annu Rev Neurosci 16:403-443.

Schoepfer R, Conroy WG, Whiting P, Gore M, Lindstrom J (1990) Brain $\alpha$-bungarotoxin binding protein cDNAs and MAbs reveal subtypes of this branch of the ligand-gated ion channel gene superfamily. Neuron 5:35-48.

Seabrook GR, Fieber LA, Adams DJ (1990) Neurotransmission in neonatal rat cardiac ganglion in situ. Am J Physiol (Heart Circ Physiol 28) 259:H997-H1005.

Séguéla P, Wadiche J, Dineley-Miller K, Dani JA, Patrick JW (1993) Molecular cloning, functional properties, and distribution of rat brain $\alpha 7$ : a nicotinic cation channel highly permeable to calcium. J Neurosci 13:596-604.
Steele PA, Gibbins IL, Morris JL, Mayer B (1994) Multiple populations of neuropeptide-containing intrinsic neurons in the guinea-pig heart. Neuroscience 62:241-250.

Steele PA, Gibbins IL, Morris JL (1996) Projections of intrinsic cardiac neurons to different targets in the guinea-pig heart. J Auton Nerv Syst 56:191-200.

Ullian EM, Sargent PB (1995) Pronounced cellular diversity and extrasynaptic location of nicotinic acetylcholine receptor subunit immunoreactivities in the chicken pretectum. J Neurosci 15:7012-7023.

Vernallis AB, Conroy WG, Berg DK (1993) Neurons assemble acetylcholine receptors with as many as three kinds of subunits while maintaining subunit segregation among receptor subtypes. Neuron 10:451-464.

Wada K, Ballivet M, Boulter J, Connolly J, Wada E, Deneris ES, Swanson LW, Heinemann S, Patrick J (1988) Functional expression of a new pharmacological subtype of brain nicotinic acetylcholine receptor. Science 240:330-334.

Wilson Horch HL, Sargent PB (1996) Perisynaptic surface distribution of multiple classes of nicotinic acetylcholine receptors on neurons in the chicken ciliary ganglion. J Neurosci 15:7778-7795.

Yuan B-Y, Ardell JL, Hopkins DA, Losier AM, Armour JA (1994) Gross and microscopic anatomy of the canine intrinsic cardiac nervous system. Anat Rec 239:75-87. 